\title{
Patient satisfaction of pterygium surgery using fibrin glue versus suture autograft
}

\author{
Nur Reza Mohamad Noh'1, Geng-Yi Yong' ${ }^{1}$, Siew-Ting Lee', Kui-Feng \\ Low ${ }^{1}$, Shin-Wei Pan ${ }^{1}$ \\ ${ }^{1}$ Department of Ophthalmology, Sibu Hospital, Sarawak, Malaysia
}

\begin{abstract}
Purpose: To compare pterygium surgery with fibrin glue autografts and sutured autografts in terms of length of surgery time and postoperative patient satisfaction.

Methods: All pterygium operations performed at Sibu Hospital (Sarawak, Malaysia) between October 1, 2012 and September 30, 2013 were included.

Results: Eighty-one cases were included in the study. The fibrin glue group and suture group had 33 and 48 cases, respectively. The mean age of the patients was 50.56 (SD: 7.61). The fibrin glue group had a shorter mean duration of surgery (17.18 minutes, SD: 10.66) compared to the suture group (22.60 minutes, SD: 12.88) $(P=0.05)$. Patient satisfaction at first week review was $93.9 \%$ for the fibrin glue group and $75.0 \%$ for the suture group ( $P=0.027$, OR 5.2 [95\%Cl: 1.1, 24.9]). Patient satisfaction at sixth week review was $97.0 \%$ for the fibrin glue group and $77.1 \%$ for the suture group $(P=0.023,0 R 9.5$ [95\%Cl: $1.2,77.8])$. There was no serious adverse event in this study population.

Conclusion: Fibrin glue has shorter mean duration of surgery and significantly higher patient satisfaction at first week and sixth week post-pterygium surgery compared to the suture technique.
\end{abstract}

Keywords: fibrin glue, pterygium, sutured autograft

\section{Introduction}

Pterygium is a fibrovascular overgrowth arising from subconjunctival tissue extending across the limbus onto the cornea. The prevalence rate of primary pterygium varies from 0.7 to $30 \%$ in various populations around the world. ${ }^{1}$ During pterygium surgery, the conjunctival autografts are secured in place either conventionally with sutures or with a newer method involving fibrin glue. There have been a few reports, namely done by Koranyi et al. ${ }^{2}$ in Sweden and Srinivasan et $a .^{3}$ in Canada, regarding the outcome from comparison studies between fibrin glue and sutured autografts. These studies are noted to have been performed in countries that have four seasons. There have not been many reports regarding postoperative satisfaction from pterygium surgery in countries that receive sun

Correspondence: Nur Reza Mohamad Noh, Medical Officer, Ophthalmology

Department, Hospital Sibu, 96000 Sibu, Malaysia.

E-mail: nurrezadr@gmail.com 
and ultraviolet exposure year-round, such as Malaysia.

Pterygium excisions in Malaysia are traditionally done with sutured autografts. Fibrin glue autografts after pterygium excisions are done in several Malaysian general hospitals, including Sibu Hospital, where the technique was introduced in March 2013.

Several patients expressed their satisfaction with the postoperative outcome of pterygium surgery with fibrin glue autografts. We hope this study may provide insight as to whether this particular type of surgery is significantly superior to conventional pterygium surgery with sutured autografts, so that pterygium excision with fibrin glue autografts may be incorporated into the general hospitals in Malaysia, thus improving outcomes and patient satisfaction.

We performed a study to compare the short-term patient satisfaction from fibrin glue autografts as compared to sutured autografts, with special emphasis on surgical time and postoperative discomfort during follow-up.

\section{Purpose}

\section{Objective}

1. To evaluate post pterygium surgery satisfaction between subjects with fibrin glue compared to subjects with suture autografts.

2. To compare the length of the surgery time between the two groups.

\section{Materials and methods}

\section{Methods}

This is a retrospective study done to compare the short-term satisfaction result of fibrin glue vs vicryl sutures for fixating conjunctival autografts in patients undergoing pterygium excision in subjects from October 1, 2012 until September 30, 2013. Case records from the Medical Records Department of Sibu Hospital provided information including demographic data, specific details of pterygium surgery (surgery duration) and patients' satisfaction in terms of symptoms (red eye, discomfort, gritty or foreign body sensation, pain and/or tearing). The entire process was conducted using a data collection form. In cases where incomplete data were encountered, or accuracy was uncertain (five cases), patients were contacted by telephone to verify the information.

Subject data for sutured autografts after pterygium excision was collected for six months between October 1, 2012 and March 31, 2013. Subject data for pterygium excision with fibrin glue was also collected for six months between April 1, 2013 and September 30, 2013. The subjects were individuals aged 31 to 60 years, with a one-sided primary pterygium (nasal or temporal only), and no other 
ocular conditions in the operated site.

Pterygium surgery was recommended to patients when the pterygium caused visual disturbance, either through pupillary aperture invasion or significantly inducing corneal astigmatism. It was also recommended if there was chronic symptomatic inflammation (significant foreign body sensation or pain, hyperemia) and causing restriction of ocular motility or is disfiguring. ${ }^{4}$

We included all pterygium surgeries done from October 1, 2012 until September 30, 2013. The exclusion criteria included secondary or recurrent pterygium, concurrent nasal and temporal pterygium, and those living outside Sibu town. Individual patients in which the eye has been operated previously for other eye conditions with scleral or conjunctival involvement, such as trabeculectomy or extracapsular cataract extraction surgeries involving the limbal area, were also excluded.

The information regarding the subjects in this study was taken from the case notes obtained from Sibu Hospital's medical records office. The first group of patients $(n=33)$ had autografts done after pterygium surgery with fibrin glue and the second group of patients $(n=48)$ had autografts done after pterygium surgery with vicryl sutures. The sutures used in this study were 8-0 coated vicryl.

\section{Materials}

1. Guttae Betacin: Guttae betamethasone sodium phosphate $0.1 \% \mathrm{bw} / \mathrm{v}$, neomycin sulphate $0.5 \% \mathrm{w} / \mathrm{v}$, benzalkonium chloride solution $0.01 \% \mathrm{~W} / \mathrm{v}$ (CCM Pharmaceuticals, Malaysia);

2. Vicryl sutures: 8-0 coated vicryl absorbable sutures (Ethicon, Johnson \& Johnson, Belgium);

3. Fibrin glue: Tisseel fibrin sealant (Baxter AG, Vienna, Austria);

4. Dental lignocaine: Mepivacaine $2 \%$ special with adrenaline 1:100 000 (Septodont, France); and

5. Surgical scalpel: Surgical scalpel blade number 15 (Ribbel Healthcare, United Kingdom, England).

\section{Surgical procedure}

The procedure was done by doctors in the Department of Ophthalmology who were credentialed to perform pterygium excision. The patient was to lie down on the operating table. Topical proparacaine hydrochloride $(0.5 \%$ alcaine, Alcon, Belgium) was instilled into the operated eye, which then underwent standard ophthalmic sterile preparation and draping. The eye was exposed using a lid speculum. An operating microscope was used. Dental lignocaine was injected to the pterygium body to make the dissection easier and act as haemostatic to prevent excessive bleeding. A surgical scalpel blade number 15 was used to excise the pterygium from the cornea and remove the surrounding Tenon's capsule. The 
body of the pterygium was excised using a pair of Westcott scissors. The bleeding vessel on the sclera was cauterized using wet field cautery.

The free conjunctival graft was obtained from the supero-temporal quadrant of the bulbar conjunctiva. Dental lignocaine was injected at the desired site. A pair of Westcott scissors was used to harvest the free conjunctival-limbal autograft. The dissected autograft was flipped over the cornea and brought near the area of bare sclera formed by the pterygium excision. Proper orientation was maintained with the limbal edge towards the limbus.

In the group using the fibrin glue autograft (FG group, $n=33$ ), the graft was placed on the cornea with the stromal side facing upwards. One or two drops of the sealant protein, or thrombin, were mounted to the graft and one or two drops of the setting solution, or fibrinogen, were mounted on the bare sclera. The autograft was then flipped over onto the bare sclera so that the two mixtures formed a strong fibrin clot. The graft was smoothed out with a non-tooth forceps.

In the group with the vicryl sutured autograft (suture group, $n=48$ ), around four to five stiches were placed to attach the autograft to the underlying episcleral bed. The sutures were anchored in place to the sclera at the limbus first with single superior and inferior buried sutures. The rest of the autograft margin was attached with two or three interrupted buried sutures.

The operating time was noted to start from the injection of dental lignocaine at the pterygium body until the removal of the lid speculum.

At the end of the surgery, chloramphenicol ointment was applied with sterile eye pad for the sutures group. In the fibrin glue group, Guttae Betacin was applied with a sterile eye pad.

\section{Postoperative evaluation}

Postoperatively, subjects in both groups were treated with Guttae Betacin every four hours for the first week, tapered down to four-times-a-day for the following two weeks. Case notes were referred at the end of the first week and sixth weeks postoperatively. The status of the autograft, donor site, and any discomforts were noted in regard to conjunctival redness, tearing of the graft from the recipient site, and graft dislocation.

\section{Ethical approval}

This study was approved by the Medical Research Ethics Committee and Ministry of Health, Malaysia (NMRR-13-1460-18201). We conducted the study according to good clinical practice and followed the guidelines of the Declaration of Helsinki.

\section{Statistical analysis}

Statistical analysis was performed using SPSS version 20. The conventional level of significance $P<0.05$ applied in all cases. 


\section{Results}

A total of 81 cases of pterygium excision were included in the study. Thirty-three cases belonged to the fibrin glue group and 48 cases to the suture group. Gender distribution was equal, with 41 males and 40 females in this study. The mean age was 50.56 years old (SD: 7.61). Detailed results of the study are shown in Table 1, Table 2, and Table 3.

From the suture group, 12 cases complained of discomfort at the end of firstweek review and 11 cases at the end of sixth-week review. Two cases complained of discomfort at the end of first-week and sixth-week review due to corneal opacity and loose sutures, respectively. Other complaints of discomfort were due to pain, broken sutures, foreign body sensation, and inflammation. Out of 11 cases, a total of 7 cases noted recurrence at the end of the sixth-week review.

Two cases from the fibrin glue group complained of discomfort at the end of the first-week review due to retracted grafts and swollen eye, which subsequently resolved by the end of the sixth-week review. However, another case reported graft gaping at the end of the sixth-week review. There was no recurrence recorded at the end of sixth-week review.

Table 1. Sociodemographic characteristics of study sample

\begin{tabular}{|l|l|l|}
\hline \multicolumn{2}{|l|}{} & Number of patients (\%) \\
\hline Gender & Male & $41(50.6)$ \\
\hline & Female & $40(49.4)$ \\
\hline Ethnicity & Malay & $6(7.4)$ \\
\hline & Chinese & $19(23.5)$ \\
\hline & Iban & $40(49.4)$ \\
\hline & Melanau & $13(16.0)$ \\
\hline & Others & $3(3.7)$ \\
\hline
\end{tabular}

Table 2. Comparison of numerical variables between methods of surgery

\begin{tabular}{|l|l|l|l|l|l|}
\hline & $\begin{array}{l}\text { Suture } \\
(\mathbf{n}=\mathbf{4 8}) \\
\text { Mean (SD) }\end{array}$ & $\begin{array}{l}\text { Fibrin glue } \\
(\mathbf{n}=\mathbf{3 3}) \\
\text { Mean (SD) }\end{array}$ & $\begin{array}{l}\text { Mean } \\
\text { differ. } \\
(\mathbf{9 5 \%} \text { Cl) }\end{array}$ & $\begin{array}{l}\mathbf{t} \text { statistic } \\
(\mathbf{d f})^{\mathbf{a}}\end{array}$ & P-valuea \\
\hline $\begin{array}{l}\text { Operation time } \\
\text { (mins) }\end{array}$ & 22.60 & $\begin{array}{l}17.18 \\
(10.66)\end{array}$ & $\begin{array}{l}5.42 \\
(0.00,10.84)\end{array}$ & $\begin{array}{l}1.99 \\
(79)\end{array}$ & 0.05 \\
\hline
\end{tabular}

andependent t-test

Table 3. Patient satisfaction associated with sutures and fibrin glue at the end of the first-week 
and sixth-week review

\begin{tabular}{|l|l|l|l|l|l|l|l|}
\hline & $\begin{array}{l}\text { Method } \\
\text { of } \\
\text { surgery }\end{array}$ & $\mathbf{n}$ & $\begin{array}{l}\text { Satisfied } \\
(\%)\end{array}$ & $\begin{array}{l}\text { Not } \\
\text { satisfied } \\
(\%)\end{array}$ & $\begin{array}{l}\text { OR (95\% } \\
\text { CI) }\end{array}$ & $\begin{array}{l}\mathbf{X}^{2} \\
\text { statistics } \\
(\boldsymbol{d f})\end{array}$ & P-value \\
\hline $\begin{array}{l}1^{\text {st }} \\
\text { week }\end{array}$ & Suture & 48 & $36(75.0)$ & $12(25.0)$ & $\begin{array}{l}5.2 \\
(1.1,24.9)\end{array}$ & $4.91(1)^{\mathrm{a}}$ & $0.027^{\mathrm{a}}$ \\
\hline & $\begin{array}{l}\text { Fibrin } \\
\text { glue }\end{array}$ & 33 & $31(93.9)$ & $2(6.1)$ & & & \\
\hline $\begin{array}{l}6^{\text {th }} \\
\text { week }\end{array}$ & Suture & 48 & $37(77.1)$ & $11(22.9)$ & $\begin{array}{l}9.5 \\
(1.2,77.8)\end{array}$ & - & $0.023^{\text {b }}$ \\
\hline & $\begin{array}{l}\text { Fibrin } \\
\text { glue }\end{array}$ & 33 & $32(97.0)$ & $1(3.0)$ & & & \\
\hline
\end{tabular}

${ }^{a}$ Chi-square test for independence bFisher's exact test

\section{Discussion}

Pterygium is a common ophthalmic condition which is easy to diagnose but difficult to treat. Various surgical techniques and their modifications have been described to manage this condition with prevention of recurrence as the underlying aim. ${ }^{5}$

The use of a conjunctival graft to cover the bare sclera after pterygium excision has been reported to be the most effective method of lowering recurrence rate and complications. ${ }^{5}$

A study by Jiang et al. in 2008 evaluated the efficacy and safety of fibrin glue in conjunctival autograft fixation in primary pterygium compared with that of suturing. ${ }^{6}$ They found that fibrin glue application takes significantly shorter operating time and is associated with fewer postoperative symptoms than a sutured graft, indicating the safety of the procedure.

The use of fibrin sealant for attaching corneal transplant in rabbits was first reported by Katzin. ${ }^{7}$ Tisseel fibrin sealant is a commercially available fibrin adhesive prepared from donor plasma and is safe as other tested blood products. ${ }^{8}$

\section{Conclusion}

Fibrin glue has a shorter mean duration of surgery and significantly higher patient satisfaction at first-week and sixth week post-pterygium surgery compared to the suture technique. 


\section{Acknowledgments}

None of the authors has a financial or propriety interest in any material or method mentioned.

We would like to thank the Director-General of Health, Malaysia for his permission to publish this report.

Furthermore, we are grateful to the Clinical Research Centre, Sibu Hospital for its continuous support of this study and to Mr Wong Siew Tung for proofreading.

\section{References}

1. Detels R, Dhir SP. Pterygium: a geographical survey. Arch Ophthalmol. 1967;78:485.

2. Koranyi G, Seregard S, Kopp ED. Cut and paste: a no suture, small incision approach to pterygium surgery. Br J Ophthalmol. 2004;88:911-914.

3. Srinivasan $S$, Dollin $M$, McAllum $P$, et al. Fibrin glue versus sutures for attaching the conjunctival autograft in pterygium surgery: Prospective observer masked clinical trial. Br J Ophthamol. 2009;93:215-218.

4. Stewart DE. System of Ophthalmology, Vol. VIII. London: Henry Kimpton; 1965:574.

5. Vichare N, Chaudhary T, Arora P. A comparison between fibrin sealant and sutures for attaching conjunctival autograft after pterygium excision. Medical Journal Armed Forces India. 692013:151-155.

6. Jiang J, Yang Y, Zhang M, et al. Comparison of fibrin sealant and sutures for conjunctival autograft fixation in pterygium surgery; one year follow up. Ophthalmologica. 2008;222:105-111.

7. Katzin HM. Aqueous fibrin fixation of corneal transplants in the rabbit. Arch Ophthalmol. 1945;35:415-420.

8. Gammon RR, Avery N, Mintz PD. Fibrin sealant: an evaluation of methods of production and the role of blood bank. J Long Term Eff Med Implants. 1998;8:103-116. 